\title{
BASH: badmouthing, attitudes and stigmatisation in healthcare as experienced by medical students
}

\author{
Ali Ajaz, ${ }^{1}$ Rhodri David, ${ }^{1}$ Damien Brown, ${ }^{2}$ Melanie Smuk, ${ }^{2}$ Ania Korszun ${ }^{2}$
}

BJPsych Bulletin (2016), 40, 97-102, doi: 10.1192/pb.bp.115.053140

${ }^{1}$ East London NHS Foundation Trust; ${ }^{2}$ Barts and The London School of Medicine and Dentistry

Correspondence to Ania Korszun (a.korszun@qmul.ac.uk)

First received 18 Nov 2015, final revision 31 Jan 2016, accepted 1 Feb 2016

(C) 2016 The Authors. This is an openaccess article published by the Royal College of Psychiatrists and distributed under the terms of the Creative Commons Attribution License (http:// creativecommons.org/licenses/by/ 4.0), which permits unrestricted use, distribution, and reproduction in any medium, provided the original work is properly cited.

\begin{abstract}
Aims and method We used an online questionnaire to investigate medical students' perceptions of the apparent hierarchy between specialties, whether they have witnessed disparaging comments ('badmouthing' or 'bashing') against other specialists and whether this has had an effect on their career choice.
\end{abstract}

Results In total, 960 students from 13 medical schools completed the questionnaire; they ranked medical specialties according to the level of badmouthing and answered questions on their experience of specialty bashing. Psychiatry and general practice attracted the greatest number of negative comments, which were made by academic staff, doctors and students. Twenty-seven per cent of students had changed their career choice as a direct result of bashing and a further $25.5 \%$ stated they were more likely to change their specialty choice. Although $80.5 \%$ of students condemned badmouthing as unprofessional, $71.5 \%$ believed that it is a routine part of practising medicine.

Clinical implications Bashing of psychiatry represents another form of stigmatisation that needs to be challenged in medical schools. It not only has an impact on recruitment into the specialty, but also has the wider effect of stigmatising people with mental health disorders.

Declaration of interest None.
Choosing a career specialty is one of the most important decisions that medical students will make and one that will shape the rest of their working lives. Some students decide early on, or even come into medical school with a good idea of what career they would like to pursue, ${ }^{1}$ yet for most students the specialty choice is made during medical school, ${ }^{2}$ with some remaining unsure into their final year and even as foundation year doctors. ${ }^{3}$ This choice is influenced by many factors, in particular the teachers the students encounter, ${ }^{4}$ experience during clinical placements, ${ }^{5}$ desired work-life balance, ${ }^{6}$ and also by gender $^{3}$ and personality. ${ }^{7}$

Psychiatry continues to face a worldwide problem with recruitment. In the UK, the Royal College of Psychiatrists has maintained an active recruitment programme for several years, but rates of students interested in psychiatry as a career remain low at $4-5 \%,{ }^{8}$ which is insufficient to meet future needs. A variety of approaches have been used to improve recruitment. Time and effort has gone into promoting psychiatry, and the misperceptions that put students off, such as that people 'don't get better' ${ }^{9}$ or psychiatry 'isn't proper medicine', ${ }^{10}$ have been successfully challenged. As psychiatrists, we constantly strive to improve our profile, our teaching and our support and mentorship of students who are interested in psychiatry. But even though psychiatrists become involved in setting the medical curriculum and integrating psychiatry into mainstream medical teaching, it is not so easy to control what else is going on in the, now long-recognised, 'hidden' curriculum. ${ }^{11}$

One aspect of this hidden curriculum is the apparent hierarchy between different specialties, with specialists making disparaging comments and 'badmouthing' or 'bashing' each other's specialty. ${ }^{12,13}$ A stable prestige hierarchy exists among medical specialties, with certain ones, such as surgery and cardiology, consistently ranked at the top and others, such as dermatology and psychiatry, consistently resting at the bottom. ${ }^{14,15}$ This has led to many enduring stereotypes of 'macho surgeons', 'fluffy psychiatrists', 'lazy dermatologists' and 'useless general practitioners'. ${ }^{12,16}$ Should these be regarded as just some fun and perhaps part of the medical tradition to which succeeding generations of medical students are inducted? Or do these attitudes actually have a detrimental effect on the students' perception and choice of some specialties?

In one large US study, ${ }^{17} 76 \%$ of students had heard badmouthing of their career choice specialty and $17 \%$ stated that this had made them alter their career choices. In a more recent survey of third-year US students, ${ }^{18}$ family medicine was the most 'bashed' specialty, but psychiatry was not far behind, with $39 \%$ of students stating that they had heard disparaging comments about psychiatry. There are no data available on how common this practice is in UK medical schools and whether it affects our students' career choices. We thus undertook an online questionnaire study 
to measure: (a) how frequently British medical students encounter badmouthing of different specialties and (b) whether witnessing badmouthing affects their choice of career specialty. Ethics approval was obtained from the Barts and The London School of Medicine and Dentistry and the Research Ethics Committee at Queen Mary University of London (Ref: QMREC 0987).

\section{Method}

We conducted a nationwide questionnaire survey of students at UK medical schools. An invitation letter and weblink to the online survey was sent to the relevant administrators at all $32 \mathrm{UK}$ medical schools asking for it to be distributed to all their students (years 1-5 and students intercalating degrees), with a reminder email sent 2 weeks later. The survey remained open for 6 months and participation was entirely on a voluntary basis. Students were informed in the invitation letter that the responses would be anonymous and all data were also stored anonymously as stipulated in the ethics approval.

\section{The questionnaire}

The online questionnaire was made available through the Survey Monkey website (www.surveymonkey.com) and questions were based on previous studies. ${ }^{18}$ In the instructions for completing the questionnaire badmouthing and bashing were defined as: 'distinctly negative feedback and comments directed by members of one medical specialty toward other specialties'. Participants were asked to complete demographic items (age, gender, medical school and year of study). Students were then asked: (a) to rank a list of medical specialties according to the level of badmouthing or negative comments that they attract (most negative comments to fewest negative comments); (b) how often the students themselves had made negative comments about these specialties (very frequently to never); and (c) to indicate the frequency of negative comments about other specialties that had been made by specific groups of individuals (academic staff, non-academic staff, doctors during clinical placement and other medical students). Participants were encouraged to provide examples of such statements in the free-text boxes. Participants were also asked to rank their level of agreement with ten statements relating to future career choice (Box 1).

Although this was not a qualitative study, participants also had the opportunity to make any additional comments on the topic of specialty badmouthing in a free-text box. These responses were reviewed to explore whether any specific patterns emerged. These were categorised and combined into overarching themes to provide further understanding of the quantitative data.

The data contained missing observations. We explored the missing data patterns and looked at predictors for being missing using logistic regression models. No strong patterns or predictors were found, which suggested that we could use complete case analysis without introducing bias. Analysis was undertaken using Fisher's exact test, Friedman test and Spearman's rank correlation to handle the ordinal nature of the data.
Box 1 Questionnaire statements relating to students' career choice

1 I've changed my career option due to hearing negative comments being made about my specialty of choice.

2 When asked about my specialty choice, I've avoided the question or misled others to avoid being treated differently.

3 I'd be more likely to change my specialty choice if I witnessed it being badmouthed.

4 Badmouthing wouldn't affect my specialty choice.

5 I think badmouthing other specialties is unprofessional.

6 Badmouthing other specialties is just a bit of fun and is part of working as a doctor.

7 I think badmouthing would affect whether somebody chooses a certain specialty.

8 Badmouthing other specialties is always going to be a part of practising medicine.

9 Doctors that badmouth other specialties are insecure about their own career choice.

10 There's an unspoken hierarchy of specialties in medicine.

\section{Results}

A total of 960 medical students completed the survey. Although every medical school in the UK was invited to take part, there was no mechanism for checking whether the administrator had forwarded the survey link to students and replies were received from students attending 13 universities. The distribution of students throughout the undergraduate medical course is shown in Table 1.

The survey did not force students to rank specialties as described in the accompanying instructions to this item. Thus, not all students followed the instructions, and the sample size for analysis for this item was decreased to 483 for students who had ranked correctly. Demographics were similar for correctly and incorrectly ranking students. The other analyses kept the cohort at $n=960$.

Table 1 Respondent demographics $(n=960)$

\begin{tabular}{|lc|} 
Table 1 Respondent demographics $(n=960)$ & $n(\%)$ \\
\hline Gender & \\
Male & $346(36.0)$ \\
Female & $614(64.0)$ \\
\hline Age, years & \\
$18-20$ & $248(25.8)$ \\
$21-29$ & $673(70.1)$ \\
$30-39$ & $34(3.5)$ \\
Over 40 & $5(0.5)$ \\
\hline Year of study & $146(15.2)$ \\
1 & $131(13.6)$ \\
2 & $145(15.1)$ \\
3 & $254(26.5)$ \\
4 & $227(23.6)$ \\
5 & $23(2.4)$ \\
Intercalated BSc & $34(3.5)$ \\
\hline
\end{tabular}


From the list of eight medical specialties provided, students reported that both psychiatry and general practice attracted the greatest number of negative comments. The difference in ranking over all groups was statistically significant (Friedman test $P<0.001$ ) and the mean ranking for each was as follows ( 1 attracts the most negative comments, 8 attracts the fewest negative comments): general practice 2.20 , psychiatry 2.29 , radiology 4.04 , surgery 4.55 , anaesthetics 5.08, obstetrics and gynaecology 5.13, emergency medicine 6.35 and hospital medicine 6.37. Psychiatry was significantly different (Wilcoxon signed rank test $P<0.001)$ from all specialties except general practice.

Participants reported hearing negative comments about different specialties made by other medical students, academic staff members (both clinical and non-clinical) whom they had encountered at university, and doctors of all grades during their clinical placements (Table 2). The highest frequency of negative comments was attributed to other medical students.

Students were asked how frequently they themselves had made comments against other specialties. Psychiatry, general practice and surgery attracted the most critical comments from the student respondents. Examples of disparaging comments were: 'psychiatrists are not actual doctors', 'psychiatry - not real medicine', 'psychiatrists are crazy themselves', 'you don't need a medical degree to be a GP', 'people become GPs when they fail all other exams'.

The association between the frequency of students hearing negative comments and the frequency of students making negative comments was explored with a Spearman's rank correlation. Students significantly $(P<0.001)$ reported higher frequencies of making more negative comments with higher frequencies of hearing negative comments.

Participant gender was not associated with making or hearing negative comments about specialties. However, there was a significant association (Fisher's exact test) between age and negative perceptions of psychiatry $(P=0.03)$, surgery $(P=0.037)$ and anaesthetics $(P=0.004)$, namely negative perceptions decreased with increasing age.

There was a significant association (Fisher's exact test) between year of study at medical school and ranking badmouthing for psychiatry $(P=0.001)$, general practice $(P=0.02)$, surgery $(P=0.008)$ and anaesthetics $(P=0.001)$. For psychiatry, negative perceptions were least frequent in the first year of medical school and most frequent in the fifth year, whereas for anaesthetics the opposite was true.

Although $80.5 \%$ of students condemned badmouthing as being unprofessional, $71.5 \%$ believed that it is an everpresent part of practising medicine; $57.3 \%$ viewed it as 'just a bit of fun'; $27.1 \%$ agreed with the statement that doctors who 'badmouth' other specialties 'are insecure in their own career choice'; and $74.0 \%$ agreed that there is an unspoken hierarchy of specialties in medicine.

When exploring the influence of badmouthing on career choice, $27.0 \%$ of students agreed that they had changed their career choice as a direct result of negative comments made about them and a further $25.5 \%$ said that they were more likely to change their specialty choice if they had witnessed it being 'badmouthed'. Over a third (36.8\%) had feared being treated differently by others when asked about their specialty choice and therefore resorted to either avoiding the question or providing misleading answers. Two-thirds (66.2\%) agreed that badmouthing against a particular specialty would affect a student's decision to choose it as a career.

\section{Thematic review of comments}

The final question of the survey asked students to make any additional statements related to specialty badmouthing. A total of 146 students made comments and these were reviewed by two researchers (A.A. and A.K.) and grouped into four main categories according to identified themes.

\section{Acceptance of badmouthing}

The majority of comments (40.4\%), either directly or indirectly, minimised any negative connotations associated with badmouthing other specialties or the impact on students' future career choices. The most frequent comments stated that badmouthing was nothing but harmless fun and was done without any maleficent intentions. There was a real sense among some students

\begin{tabular}{|c|c|c|c|}
\hline & Frequently, \% & Sometimes, \% & Never, \% \\
\hline \multicolumn{4}{|c|}{ How often do you hear people make negative comments about other specialties? } \\
\hline Medical students & 44.7 & 52.1 & 3.2 \\
\hline Consultants during placements & 32.8 & 57.1 & 10.2 \\
\hline Registrars during placements & 26.8 & 63.1 & 10.2 \\
\hline Junior doctors during placements & 20.1 & 70.0 & 9.9 \\
\hline \multicolumn{4}{|l|}{ Academic staff } \\
\hline Medical (e.g. professors, clinical lecturers) & 19.6 & 72.8 & 7.6 \\
\hline Non-medical (e.g. non-clinical lecturers) & 10.5 & 75.4 & 14.1 \\
\hline \multicolumn{4}{|c|}{ How often do you personally make negative comments about the following specialties? } \\
\hline Surgery (e.g. ENT, orthopaedics) & 9.6 & 56.4 & 34.1 \\
\hline General practice & 9.1 & 59.3 & 31.6 \\
\hline Psychiatry & 7.3 & 57.0 & 35.7 \\
\hline Radiology & 3.8 & 50.6 & 45.5 \\
\hline Obstetrics and gynaecology & 3.2 & 46.8 & 50.1 \\
\hline Anaesthetics & 2.8 & 44.5 & 52.7 \\
\hline Hospital medicine (e.g. cardiology, respiratory medicine) & 1.5 & 43.2 & 55.3 \\
\hline Emergency medicine & 1.1 & 35.6 & 63.4 \\
\hline
\end{tabular}

ENT, ear, nose and throat. 
that badmouthing was beneficial as a source of conversation and bonding within clinical teams. There was some recognition that some medical students might be influenced by the negative comments about certain specialties, but this was dismissed as being due to their own insecurities about their career choice rather than being affected by the remarks.

'Almost every specialty badmouths at least one other - in a way this is good as it allows us as medical students to make an informed choice.'

'Playful banter between different specialties . . . can be a topic of conversation which bonds medical staff together.'

'I feel that if you like a specialty enough, what people say is never going to change how you feel.'

'Harmless bit of fun . . . more like teasing than anything, although it could offend someone who is insecure about their career choice.'

\section{Negative effects of badmouthing}

Some students admitted to having rejected certain specialties as career options because of experiencing negative comments, either about the nature of the work or personal qualities of doctors who choose that field. The most commonly mentioned specialties were psychiatry, general practice and dermatology. Other students reported that they purposefully kept their career choice to themselves because of fear of discrimination by their peers or clinicians at their clinical placements. Some participants condemned all types of badmouthing and believed it to be unprofessional.

'Badmouthing of GPs has put me off going into it as much as it
seems less respected professionally and doctors don't give as much credit to [the GPs'] findings as they should.'

'I have heard consultants refer to GPs like idiots . . . It makes it a really difficult career to feel good about going into and is making me wonder whether after all the hard work at medical school I want to go into a career where I'm not respected and I'm almost a level below hospital doctors.'

'If I am asked by a clinical member of staff . . . I very often do not tell them that I have an interest in psychiatry, as I feel that this may mean that I am judged automatically about my knowledge, skills and attitude towards medicine in general.'

'It's unethical and therefore fundamentally undermines a health professional's code of conduct.'

\section{Grey area of acceptability}

Some students raised the issue of distinguishing degrees of badmouthing that are acceptable. Some believed that there was a 'fine line' between comments made in jest and those that were damaging to other specialties. There were some views that badmouthing at undergraduate level was nothing but 'harmless banter', whereas similar comments by qualified doctors were considered to hold more weight and be more influential and therefore unprofessional. Others stated that any badmouthing was both harmless and acceptable in medical circles, however, anything that extended to (or was overheard by) members of the general public was inappropriate. One student stated that medical students were relatively immune to the negative effects of badmouthing because they were still 'explorers' (on the path of choosing a career specialty) and that doctors in training were the ones who were more vulnerable to changing their choice of career in response to badmouthing by their more senior colleagues.

'Most of the badmouthing heard within the student generation is usually a bit of fun and not meant in seriousness. The genuine badmouthing is heard at higher levels, i.e. senior registrar or consultant.'

'I think it is important to distinguish between badmouthing which can be unprofessional and banter between specialties which is part of the job - there is a fine line.'

\section{Addressing bashing}

There were comments that specialty badmouthing is an ingrained and accepted part of the culture in medicine for students and doctors. Thus, there was an element of helplessness expressed by some students in considering how to overcome this practice. The main suggestions focused on raising awareness of its negative effects and the need to educate students and doctors of the value of each specialty and how any form of badmouthing (regardless of the intention) is a breach of medical professionalism.

\begin{abstract}
. . . badmouthing is so much part of what doctors and surgeons talk about that it would be difficult to stop it completely, but maybe raising awareness that it does affect which specialty students may go into in the future would make them think about what they say and how they say it more.'
\end{abstract}

'I don't see a way it can be altered. It's tradition - hard to change.'

"There ought to be efforts made to challenge the mentality of the "hierarchy of specialties" and broaden the horizons of what medical students think about different specialties.'

\section{Discussion}

The sample of students taking part in this study came from 13 medical schools and included students from all medical school years, with a representative age range. The larger proportion of women in the sample makes it less representative of the student population but is consistent with generally greater participation of women in online surveys. $^{19}$

In this sample of UK medical students, the specialties significantly attracting the most negative comments were psychiatry and general practice, similar to the findings in a group of third-year US students. ${ }^{18}$ The more senior the students, the more likely they were to have encountered psychiatry bashing and fifth-year medical students reported the highest levels. This may just reflect the fact that they have been around longer so have had more opportunities to come across this, but it could also indicate that this behaviour becomes more ingrained as students progress through medical school. There was no gender difference found in this sample.

Making disparaging comments was not limited to any particular group and students reported university academic staff (both clinical and non-clinical) and doctors of all grades during their clinical placements bashing their colleagues from other specialties. However, it was other medical students that were reported to make the most comments. This could be just because students encounter 
many more students than they do senior doctors and academics, but, nevertheless, this supports the fact that bashing is alive and well among our next generation of doctors. Survey participants also admitted that they themselves had made negative comments about certain specialties and there was a significant association between making and hearing badmouthing. Although career choice is obviously an important topic for discussion, it would be disappointing if this consists only of a bashing competition.

Psychiatry and general practice were the most bashed specialties, but other specialties also attracted an array of disparaging comments that reflect the stereotyping that still exists within medicine, such as 'surgery - workaholic and rubbish with patients', 'radiology - boring', 'surgeons lacking social skills, being obsessed with cutting, thinking they were God's gift', 'dermatology - derma-holiday'. Clearly, students show some confusion about this behaviour: $81 \%$ condemned it as unprofessional, but $72 \%$ believed that it is an integral part of medicine and over half thought that it is 'just a bit of fun'. In the free-text remarks, students talked about the need to take part in bashing to 'bond within clinical teams', suggesting that part of the hidden curriculum involves social coercion to 'bash' others. There are further justifications of this behaviour in that it only affects those who are insecure about their choice of specialty' - the latter of course applies to anyone who is still in the process of choosing.

But what is a bit of fun to some students clearly has a major impact on others $(27 \%)$ who reported that they had changed their career choice as a direct result of negative comments. Over a third of students avoided disclosing their choice as they feared being treated differently and twothirds agreed that bashing could affect students' decisions about careers. It is clearly unacceptable for students not to feel able to be open about their career choice in medical school. But students also highlighted the grey area between degrees of badmouthing with a 'fine line' existing between comments that are made as 'harmless banter' and those that could be damaging to other specialties. An important question is where should that line be drawn? Also, are there certain specialties that are more prone to bashing, preventing students from disclosing their interest in them because of attached stigma or perceived low status? It was clear that disparaging comments made by qualified doctors held more weight than those made by students.

It is well known that there is stigma associated with psychiatry and psychiatrists. ${ }^{20,21}$ But the disparaging comments made about the specialty (e.g. 'not real medicine') are not just stigmatising to psychiatrists, but have the wider effect of stigmatising people with mental health disorders (e.g. 'psychiatry - worse than their patients', 'psychiatrists are crazy themselves'). Both psychiatry and general practice are currently experiencing a crisis of low recruitment. Mental health disorders are highly prevalent in our population and this will have a profound effect on those affected. If mental health services are unavailable because there is a shortage of psychiatrists, then further burden will fall on general practice, which is in turn suffering a recruitment crisis and widespread bashing. At a time when public support is growing for challenging the stigma associated with psychiatric conditions and the government has stated its commitment to achieving parity of services for people with mental health disorders, it is disheartening that we still have to overcome the stereotyping and stigmatisation of psychiatry by our colleagues from other medical specialties.

\section{Study limitations}

There could have been bias in the students who responded. Because ethics allowed us only to send the link to the named administrator at each medical school office, we could not make sure that the link was forwarded to all available students. We are therefore unable to say accurately what the response rate was. However, the spread in age and year of study was good and $64 \%$ women in the sample, although also a limitation, is typical of such online surveys. Furthermore, there is a possibility that students could have responded to the questionnaire more than once, although there was no incentive for them to do so.

The questionnaire contained a short explanation of what is meant by bashing but different students may interpret this term differently.

Only some of the respondents gave free-text responses and other than identifying the four thematic groupings there was no formal qualitative analysis of these responses. However, the identification of the themes is useful in interpreting the quantitative findings and to inform future studies.

\section{Conclusions and future work}

Despite the limitations of this initial study examining the prevalence and effects of specialty bashing on career choice, there is clear evidence of bashing throughout the medical school course by all groups of students and teachers. Although some students see it as an integral part of medical school life, a third are put off their career choices. More work needs to be done to look in detail at the effects of bashing and to confirm whether these findings are generalisable. But there is clearly no time to lose in challenging bashing, which represents another form of stigmatisation of psychiatry and those with psychiatric disorders.

We need to find an effective means of challenging the belief that this behaviour is an ingrained and accepted part of our medical culture. The fact that it is mainly students who are engaging in it presents an immediate opportunity for us to have a grassroots campaign that addresses these questions and challenges the perception that it is fine to disparage certain specialties. This can only be achieved through open discussion and by raising awareness of the detrimental effects of bashing. Where should the line be drawn between friendly banter and abuse? How does bashing fit in with medical professionalism that requires showing respect for all patients and for all colleagues in our own and other specialties? Most importantly, how should students challenge bashing when they come across it? Students need to feel empowered to challenge this because there is clear and open condemnation of this behaviour by their medical school. 


\section{About the authors}

Ali Ajaz is a consultant forensic psychiatrist and Rhodri David is a consultant psychiatrist at East London NHS Foundation Trust. Damien Brown is a year 5 medical student at Barts and The London School of Medicine and Dentistry. Melanie Smuk is a research fellow in medical statistics and Ania Korszun is Professor of Psychiatry and Education at the Centre for Psychiatry, Wolfson Institute of Preventive Medicine, Barts and The London School of Medicine and Dentistry, Queen Mary University of London.

\section{References}

1 Goldacre MJ, Turner G, Lambert TW. Variation by medical school in career choices of UK graduates of 1999 and 2000. Med Edu 2004; 38: 249-58.

2 Halder N, Hadjidemetriou C, Pearson R, Farooq K, Lydall GJ, Malik A, et al. Student career choice in psychiatry: findings from 18 UK medical schools. Int Rev Psychiatry 2013; 25: 438-44.

3 Goldacre MJ, Goldacre R, Lambert TW. Doctors who considered but did not pursue specific clinical specialties as careers: questionnaire surveys. J R Soc Med 2012; 105: 166-76.

4 Lunn B. Recruitment into psychiatry: an international challenge. Aus NZ J Psychiatry 2011; 45: 805-7.

5 Farooq K, Lydall GJ, Malik A, Ndetei DM, Bhugra D. Why medical students choose psychiatry - a 20 country cross-sectional survey. BMC Med Edu 2014; 14: 12.

6 Goldacre MJ, Kurina LM, Wotton CJ, Yeates D, Seagroat V. Schizophrenia and cancer: an epidemiological study. Br J Psychiatry 2005; 187: 334-8.

7 Markert RJ, Rodenhauser P, El-Baghdadi MM, Juskaite K, Hillel AT, Maron BA. Personality as a prognostic factor for specialty choice: a prospective study of 4 medical school classes. Medscape J Med 2008; 10: 49 .

8 Goldacre MJ, Fazel S, Smith F, Lambert T. Choice and rejection of psychiatry as a career: surveys of UK medical graduates from 1974 to 2009. Br J Psychiatry 2013; 202: 228-34.
9 Calvert S, Sharpe M, Power M, Lawrie S. Does undergraduate education have an effect on Edinburgh medical students' attitudes to psychiatry and psychiatric patients? J Nerv Ment Dis 1999; 187: 757-61.

10 Rajagopal S, Singh Rehill K, Godfrey E. Psychiatry as a career choice compared with other specialities: a survey of medical students. Psychiatr Bull 2004; 28: 444-6.

11 Hafferty FW. Beyond curriculum reform: confronting medicine's hidden curriculum. Acad Med 1998; 73: 403-7.

12 Creed PA, Searle J, Rogers ME. Medical specialty prestige and lifestyle preferences for medical students. Soc Sci Med 2010; 71: 1084-8.

13 Mahood S. Medical education: beware the hidden curriculum. Can Fam Physician 2011; 57: 983-5.

14 Oxtoby K. Do the classic specialty stereotypes still hold true for today's doctors? BMJ Careers 2013, 17 Dec.

15 Bellodi PL. The general practitioner and the surgeon: stereotypes and medical specialties. Rev Hosp Clin Fac Med Sao Paulo 2004; 59: 15-24.

16 Album D, Westin S. Do diseases have a prestige hierarchy? A survey among physicians and medical students. Soc Sci Med 2008; 66: 182-8.

17 Hunt DD, Scott C, Zhong S, Goldstein E. Frequency and effect of negative comments (badmouthing) on medical students' career choices. Acad Med 1996; 71: 665-9.

18 Holmes D, Tumiel-Berhalter LM, Zayas LE, Watkins R. Bashing of medical specialties: students' experiences and recommendations. Fam Med 2008; 40: 400-6.

19 Smith WG. Does Gender Influence Online Survey Participation? A RecordLinkage Analysis of University Faculty Online Survey Response Behavior. San Jose State University, 2008 (http://files.eric.ed.gov/fulltext/ ED501717.pdf)

20 Gaebel W, Zaske H, Zielasek J, Cleveland HR, Samjeske K, Stuart H, et al. Stigmatization of psychiatrists and general practitioners: results of an international survey. Eur Arch Psychiatry Clin Neurosci 2015; 265: 189-97.

21 Sartorius N, Gaebel W, Cleveland HR, Stuart H, Akiyama T, ArboledaFlorez J, et al. WPA guidance on how to combat stigmatization of psychiatry and psychiatrists. World Psychiatry 2010; 9: 131-44. 